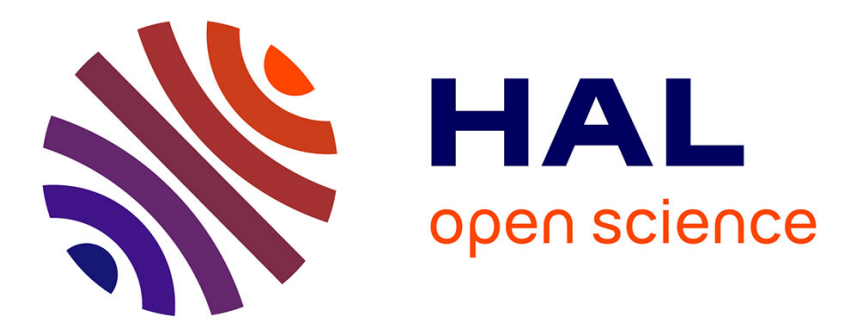

\title{
Biopolymer Systems in Soft Tissue Engineering: Cell Compatibility and Effect Studies Including Material
}

Cordula S. Hege, Dorothea Siegel-Axel, Konrad Kohler, N. Delorme, Vincent Le Houerou, Stefan Schiller, Jürgen H. Dolderer

\section{To cite this version:}

Cordula S. Hege, Dorothea Siegel-Axel, Konrad Kohler, N. Delorme, Vincent Le Houerou, et al.. Biopolymer Systems in Soft Tissue Engineering: Cell Compatibility and Effect Studies Including Material. ACS Applied Polymer Materials, 2020, 2 (8), 10.1021/acsapm.0c00359 . hal-03083263

\section{HAL Id: hal-03083263 https://hal.science/hal-03083263}

Submitted on 18 Dec 2020

HAL is a multi-disciplinary open access archive for the deposit and dissemination of scientific research documents, whether they are published or not. The documents may come from teaching and research institutions in France or abroad, or from public or private research centers.
L'archive ouverte pluridisciplinaire HAL, est destinée au dépôt et à la diffusion de documents scientifiques de niveau recherche, publiés ou non, émanant des établissements d'enseignement et de recherche français ou étrangers, des laboratoires publics ou privés. 


\section{Biopolymer Systems in Soft Tissue Engineering - Cell Compatibility \& Effect Studies Including Material-, Catalyst- and Surface Properties}

Cordula S. Hege, Dorothea Siegel-Axel, Konrad Kohler, Nicolas Delorme, Vincent Le Houerou, Stefan M. Schiller*, Jürgen H. Dolderer*

Dr. Juergen H. Dolderer, MD, PhD, FACS

University of Regensburg

Department of Plastic Surgery

Franz-Josef-Strauß-Allee 11

D-93053 Regensburg

Email: drdolderer@hotmail.com

Dr. Cordula S. Hege,

University of Freiburg - IMTEK. Department of Microsystems Engineering,

Chemistry and Physics of Interfaces,

Georges-Koehler-Allee 103 ,

D-79110 Freiburg, Germany

Dr. Cordula S. Hege, Dr. Stefan Schiller

Freiburg Institute of Advanced Studies (FRIAS)

Albertsr. 19

D -79104 Freiburg, Germany

E-mail: Stefan.Schiller@zbsa.uni-freiburg.de

Prof. Dorothea Siegel-Axel

Department of Internal Medicine IV

University of Tübingen

Otfried-Müller-Straße 10

D-72076 Tübingen, Germany

Prof. Konrad Kohler

Zentrum für Regenerationsbiologie und Regenerative Medizin

Universitätsklinikum Tübingen

Paul-Ehrlich-Straße 15

D-72076 Tübingen, Germany

Nicolas Delorme, $\mathrm{PhD}$

LPEC, UMR-CNRS 6087

Université du Maine

Avenue O. Messiaen,

F-72085 Le Mans, France

Vincent Le Houerou

Institut Charles Sadron (I.C.S.) - CNRS UPR 022

Equipe Mécanique-Physique des Polymères, 23

rue du Loess - BP 84047 
F - 67034 Strasbourg cedex 2, France

Dr. Stefan Schiller

ZBSA (Zentrum für Biosystemanalyse)

Albert-Ludwigs-Universität Freiburg

Habsburgerstr. 49

D-79104 Freiburg, Germany

Keywords: biomaterials; biopolymer, biocompatibility; polyesters; tissue engineering; surfaces

\section{ABSTRACT}

Cell compatibility of biomaterials is one of the most important issues in Tissue Engineering. It is affected by the catalyst, the chemical composition and the surface topography of the material. Our aim was to study the influence of these factors for three standard FDA-approved biopolymers on the proliferation of preadipocytes. The analyzed materials were polyesters, which were synthesized by ring-opening polymerization. Tin(II)octanoate is the standard catalysts for the ring-opening polymerization (ROP); however, considered to be cytotoxic. Therefore, we compare its compatibility with iron catalysts. Our study suggests that neither polymers nor catalysts or mechanical properties have a significant impact on cell compatibility in short term 2D cell cultures in vitro. In contrast, nanoroughness can influence how cells attach and spread in a material, showing an influence on preadipocyte proliferation. Higher nanoroughness leads to higher cell compatibility, which becomes more pronounced with time. 


\section{Introduction}

Cell compatibility is one of the most important preconditions for the use of biopolymers in tissue engineering. Biopolymers can be divided into natural biopolymers like collagen and synthetic biopolymers. Among the synthetic biopolymers, poly( $\varepsilon$-caprolactone), poly(lactide) and poly(glycolide) are the most commonly used in tissue engineering since they are FDAapproved while poly(lactide) has also found wide application in daily products. In addition, they span a wide range of degradation times and elastic properties. Moreover, their different degradation times allow to adapt their use in many different applications: from fast degrading sutures made of poly(glycolide) to slow degrading contraceptive devices made of poly $(\varepsilon-$ caprolactone). ${ }^{[1,2]}$

Even though these biopolymers found widespread applications in the biomedical filed, their diversity in terms of their chemical nature (homo- or copolymers), chemicals used during synthesis (e.g. catalysts), as well as material properties resulting from polymer processing (e.g. surface topography/roughness) create a vast parameter range impacting cells, which has not yet been analyzed in concert to verify if critical differences occur and which limitations or freedom for material choices may exist (Scheme 1).

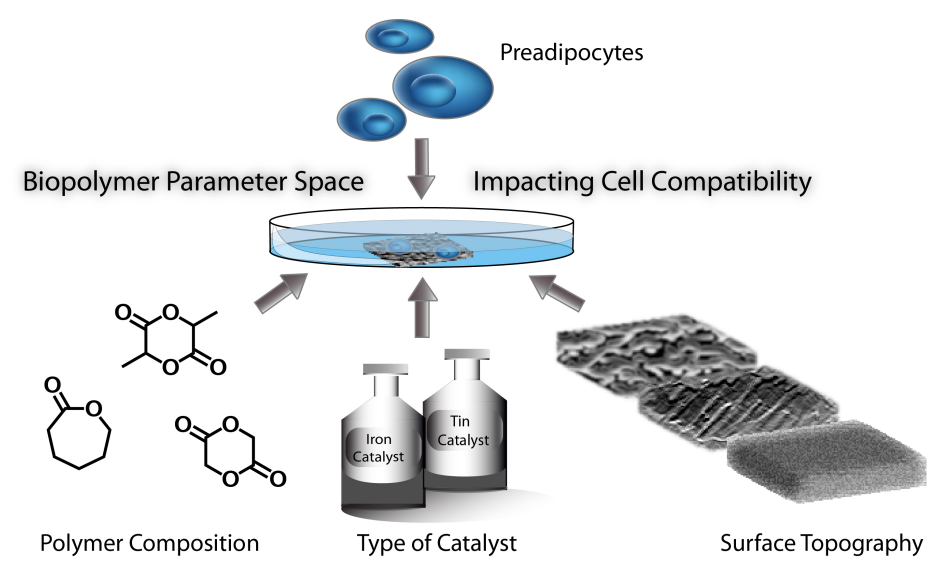

Scheme 1: Biopolymers parameter space impacting cell compatibility: composition, catalyst used in ring-opening polymerization and surface topography can affect cells - in this study 
preadipocytes were used. On the lower left the three biopolymer constituting monomeric building blocks used for biopolymer synthesis are depicted: $\varepsilon$-caprolacton,, D,L-lactic acid and glycolide. The latter were used to prepare poly(DL-lactide) and poly( $\varepsilon$-caprolactone) homopolymers, as well as all copolymers combinations of the three monomers to binary copolymers and the ternary copolymer comprising all three monomers (see Table $1 \& 2$ ).

Synthetic biopolymers are usually polymerized with tin(II)octanoate as a catalyst. However, this catalyst is considered to be cytotoxic. ${ }^{[3]}$ As a consequence, other catalysts like rare earth metals, iron, zinc or organo-catalytic systems or enzymes were examined. ${ }^{[4-8]}$

Many studies compare the cell compatibility of different polymers, ${ }^{[9-12]}$ but to our knowledge there are only a few studies which examine the cell compatibility of the catalysts, too. ${ }^{[3,13]}$ Especially there are nearly no studies with a combined scope of the effect of surface topography and polymer identity/composition on cell proliferation. The choice for preadipocytes as cellular test system scan derives from their large potential in soft tissue engineering because of their potential to differentiate into different tissues. However, to the best of our knowledge there is no study analyzing cell compatibility of a combined approach including polymer identity/composition, catalyst and surface topography towards these cells.

Our main objective is to develop favourable scaffolds and growth chambers for soft tissue engineering composed of synthetic biopolymers. To achieve this goal, it is important to analyze the impact of polymers and catalysts towards cell compatibility. As it is hardly possible to completely remove tin(II)octanoate from the polymer, a potential influence towards cell compatibility has to be assumed. ${ }^{[14]}$ 
Schappacher et al. analysed the cell compatibility of several catalysts, by examining samples made with different catalysts with the finding that none of them were toxic. ${ }^{[13]}$ However Tanzi et al. analyzed four different catalyst including tin(II)octanoate and found that this is the second most toxic catalyst among them. ${ }^{[3]}$ Until now there is no study, which compares tinand iron catalysts.

Concerning the cell compatibility of polymers, the current studies can be divided into in vitro and in vivo analyses or both simultaneously. In vitro studies do not show great differences between the cytocompatibility of different biopolymers. ${ }^{[10-12]}$ Brackett et al. analyzed endodontic materials for 6 weeks including poly( $\varepsilon$-caprolactone $)$, indicating that $\operatorname{poly}(\varepsilon-$ caprolactone) is non-cytotoxic, and was one of the best materials tested. ${ }^{[16]}$ In the case of clinical application of poly(lactide), swellings could be observed three years after operation, induced by the degrading polymer. ${ }^{[17]}$ Kobayashi et al. performed toxicity tests using implanted biodegradable polymers in rabbit cornea and found that biodegradable cyanoacrylates cause severe inflammation. ${ }^{[18]}$ Other in vivo tests were conducted by implantation of biopolymers into animals: the implants were analyzed using different methods, most importantly histologically. Investigated biopolymers such as PLA mainly showed good biocompatibility. ${ }^{[19,20]}$ Until now there is no study, which analyzes the cell compatibility of different types of polymers with preadipocytes.

The effect of the substrate topography was investigated in cell-culture experiments. For example, it was shown that osteoblasts prefer surfaces with micro-roughness in contrast to fibroblasts. ${ }^{[21,22]}$ However, if surfaces with different nanoroughnesses are compared, the fibroblasts prefer rougher surfaces. ${ }^{[2]}$ For osteoblasts a combination of both nanoroughness and microroughness enhances differentiation. ${ }^{[23]}$ Neither the effects of nanoroughness nor the effects of microroughness on preadipocytes are described in the literature yet.

Due to their importance in soft tissue engineering, preadipocytes were chosen for our study. In this paper, we analyzed the influences of the following factors on preadipocyte 
compatibility: biopolymer type, catalyst, and (nano)roughness. Although several previous studies reported in the literature, examine one of the mentioned issues, as far as we know the present study is the first one that addresses all three aspects at once. We examined different polymers and copolymers made of $\varepsilon$-caprolactone, DL-lactide and glycolide. While their influence was already analyzed towards other cells, it was not yet analyzed towards preadipocytes.

\section{Experimental Section}

\subsection{Materials}

Iron(II)bromide anhydrous $+98 \%$ was purchased from Alfa Aesar and used as received. DLlactide and benzyl alcohol were purchased from Sigma-Aldrich and used as received. Iron(III) perchlorate from Aldrich was dried in vacuum prior to use and stored in a baked-out Schlenkflask under nitrogen. $\varepsilon$-Caprolactone was dried over $\mathrm{CaH}_{2}$, distilled two-times and stored over molecular sieve and under nitrogen atmosphere in a baked-out Schlenk-flask. Chloroform from VWR was used as received. Methanol (VWR) was used as technical grade.

\subsection{Preparation of Polymers}

The polymers were synthetized by Ring-Opening-Polymerization (ROP).

A 25-50 ml flask was baked out three times and flushed with nitrogen. The solid chemicals were weighed on a weighing boat and added to the flask. The liquid monomers were continuously kept under nitrogen atmosphere. They were added with Eppendorf microliter pipettes. Last the initiator was added. Usually the ratio (2000:1:2, M:C: I) was used; however, if the molecular weight was not high enough with this ratio, a ratio of (2000:1:5) was used instead.

For example, to a solution of $6.6 \mathrm{ml}(6.85 \mathrm{~g}, 0.06 \mathrm{~mol})$ E-caprolactone, $9.7 \mu \mathrm{l}(12.15 \mathrm{mg}, 30$ $\mu \mathrm{mol}) \mathrm{Sn}(\text { octanoate })_{2}$ and $6.2 \mu \mathrm{l}(6.5 \mathrm{mg}, 60 \mu \mathrm{mol})$ benzyl alcohol were added. For other 
polymers or copolymers, the same polymerization scheme was used. The flask was sealed, evaporated and flushed with nitrogen three times. The reaction was stirred at $140^{\circ} \mathrm{C}$ in an oil bath.

The raw product was dissolved in chloroform and poured into cold methanol in $50 \mathrm{ml}$ falcon tubes. ( $3 \mathrm{ml}$ of polymer solution to $25 \mathrm{ml}$ of cold methanol). The falcon tube was centrifuged for $15 \mathrm{~min}$ at $12,000 \mathrm{rpm}$. Methanol was decanted and the polymer dissolved in chloroform. The chloroform was evaporated and the polymer dried until a constant weight was reached. Polymer chain lengths were characterized with PSS GPC SeCcurity and polystyrol standards. NMR spectra of yielded polymers were analyzed using a Bruker AVII-300 MHz.

\subsection{D-Spin-Coats}

\subsubsection{Plasma-cleaned glass-slides}

The glass slides (VWR, $3 \mathrm{~cm}$ diameter, ECN 631-1585) were cleaned with acetone and a lintfree paper (VWR, Kimberly Clark, Kimcare). Then the cleaning process was continued by exposure to oxygen plasma (Femto $100 \mathrm{~W}$, Diener electronic, Germany) for $300 \mathrm{~s}$.

A $2 \%$ polymer solution in chloroform was prepared. The glass slides were spin-coated (Spincoater Model P6700, Speciality Coating System Inc.) at $200 \mathrm{rpm}$ for $5 \mathrm{~s}$ and then 12000 rpm for $20 \mathrm{~s}$. A volume of $120 \mu \mathrm{l}$ to $150 \mu \mathrm{l}$ of polymer solution was used, adjusted to the viscosity of the polymer solution.

\subsubsection{Functionalized glass slides}

To verify, if the adhesion of the polymers to the glass slides can be enhanced, the glass slides were functionalized with silanes. The glass slides were cleaned with acetone and a lint-free paper (VWR, Kimberly Clark, Kimcare) and afterwards cleaned with Caro's acid (sulfuric acid with hydrogen peroxide) for 30 minutes. The glass slides were rinsed four times with distilled water and dried with compressed air followed by silanization for 2 hours with toluene:hexamethyldisilane (4:1). After this step, they were rinsed 4 times with distilled water 
and dried with compressed air. The spin-coating process was the same as described for plasma-cleaned glass-slides. The films were spincoated using the spin coater SCC 200 KLM with a volume of $120 \mu \mathrm{l}$ to $150 \mu \mathrm{l}$ of polymer solution, adjusted to the viscosity of the polymer solution.

\subsection{Mechanical Measurements}

Topography and film thickness were investigated by Atomic Force Microscopy (AFM) in intermittent contact mode in air with an AFM5500 (Agilent). Image processing and film thickness measurements were performed with Gwyddion software. All AFM force curves were taken in contact mode with a Z-closed loop system. Spring constants of silicon rectangular cantilevers $(\mathrm{k}=2.1 \mathrm{~N} / \mathrm{m})$ used in this study were calibrated using thermaloscillation. ${ }^{[24]}$ The tip radii $(\mathrm{R}=15-20 \mathrm{~nm})$ were measured by blind reconstruction of the tip geometry. ${ }^{[25]}$

The characterization of hardness $\mathrm{H}$ and Young's modulus $\mathrm{E}$ were performed using an ultra nanoindenter from CSM-Instruments (Switzerland). The standard instrumented indentation tests were driven at constant load rate/load of $0.05 \mathrm{~s}-1$ during both loading and unloading phases. Five different maximum loads were chosen: $0.1,0.25,0.5,1.5$ and $25 \mathrm{mN}$ corresponding to a maximum penetration depth of about $2.5 \mu \mathrm{m}$ while a principle limitation in our samples is based on the thin polymer thickness. A constant load step of $200 \mathrm{~s}$ was achieved before unloading. Each test was performed three times to ensure reproducibility. Results reported here are averages and were calculated following the procedure described in the literature. ${ }^{[26]}$

\subsection{Cell culture}

\subsubsection{Human preadipocytes}

Fat tissue was obtained during surgery of the abdomen and used with the informed consent of the patient. Subcutaneous human preadipocytes were isolated as described in the literature. ${ }^{[27]}$ 
The cells were immediately stored in $200 \mathrm{ml} \alpha$-Minimal Essential Media ( $\alpha$-MEM, Lonza). To the media was added $200 \mathrm{ml}$ Hams F12 Nutrient Mixture (Lonza), $100 \mathrm{ml}$ Fetal bovine serum (FBS, Biochrom), $5 \mathrm{ml}$ chicken embryo extract (Seralab), Glutamine (Biochrom), $5 \mathrm{ml}$ Penicillin Streptomycin (Pen-Strep, Biochrom) and $5 \mathrm{ml}$ Amphotericin B (Ampho B, Biochrom). After 70-80\% confluence the cells were frozen in liquid nitrogen. The cells were seeded at a concentration of $5^{*} 10^{4}$ cell per well. They were seeded on the spin-coated $3 \mathrm{~cm}$ glass plates, placed in 6-well dishes (TPP).

\subsubsection{Rat preadipocytes}

Rat preadipocytes were isolated from of Sprague-Dawley-rats, which were killed before. For isolation of the cells the same procedure as for human preadipocytes were used. ${ }^{[27]}$ The cells were stored in medium 199 (Lonza) supplemented with 1\%-Pen-Strep (Biochrom) and 10\%FBS. Media were changed the next day. After $70-80 \%$ confluency the cells were frozen in liquid nitrogen. The cells were seeded at a concentration of $5^{*} 10^{4}$ cell per well. They were seeded on the spin-coated $3 \mathrm{~cm}$ glass plates, in 6-well dishes (TPP).

\subsubsection{Cell counting}

Dead cells swimming in the medium were extracted by suction. The living cells were trypsinized and suspended in the cell media mentioned above. The cell compatibility was analyzed by cell counting using a hemocytometer.

\subsubsection{Differentiation}

Human preadipocytes were seeded on spin-coated glass slides at concentration of $5^{*} 10^{4}$ cell per well. The cells were differentiated in media consisting of $50 \mathrm{ml}$ Dulbeccos Modified Eagle Medium (DMEM) (Lonza) and $50 \mathrm{ml}$ Hams F12 Nutrient Mixture (Lonza), supplemented with 1ml glutamine (Biochrom), $1 \mathrm{ml}$ Pen-Strep (Biochrom), $200 \mu 1$ Ampho B (Biochrom), $100 \mu 1$ calcium D-pantothenate (Sigma-Aldrich), $1 \mu 1$ Biotin (Serva), $200 \mu 1$ human apotransferrin (Sigma-Aldrich) and $400 \mu 1$ Insulin Rapid (Sanofi). In the first week of 
differentiation the cells were cultured in a solution containing the media, $1.5 \mathrm{ml}$ FBS $(5 \%$, Biochrom), $600 \mu \mathrm{l}$ isobutyl-1-methylxanthine (IBMX, Serva), $30 \mu 1$ cortisol (Sigma-Aldrich), $30 \mu 1$ Troglitazon (trogli, Sigma-Aldrich) and $150 \mu 1$ indomethacin (Sigma-Aldrich). In the second week only $1.5 \mathrm{ml} \mathrm{FBS} \mathrm{(5 \% ,} \mathrm{Biochrom)} \mathrm{and} 30 \mu 1$ trogli (Sigma-Aldrich) were added to the media.

The cells were stained with oilred. The surfaces with differentiated adipocytes were photographed in $4 \mathrm{x}$ and 10x magnification. The pictures were analyzed using ImageJ and the cells counted with the cell counting plugin.

\subsubsection{Statistic section}

The results were analyzed with one-way ANOVA. The calculations were performed with Rstudio. ${ }^{[28]}$ The $p$-value for significance was defined as $p=0.05$. To be able to speak of a tendency for one possibility, an additional $p$-value of $p=0.3$ was defined. Additionally, when statistical significance or tendency is obtained, a Tukey HSD is performed.

\section{Results and Discussion}

The cell compatibility experiments, were composed of two sets of experiments, one with human preadipocytes (with the plasma-cleaned glass slides), the other with rat preadipocytes (with silanized glass slides). The second set of experiments was performed with rat preadipocytes due to limited access to human preadipocytes. The cells were isolated from five genetically identically Sprague-Dawley rats and not pooled. To isolate rat preadipocytes the rats were killed in accordance with the animal welfare officer of the University Tübingen and approval of the regional administrative authority Tübingen.

To verify if mechanical or topological qualities have an impact mechanical and topological measurements were made with AFM and AFM indentation. AFM indentation was used to measure the hardness and Young modulus (elasticity). In case of some polymer samples it 
was hard to measure the mechanical properties of the films, because of not sufficient height of the film or inhomogeneity.

Poly(DL-lactide) samples gave improper results probably because of the morphology of the film: it is highly inhomogeneous so that the mechanical property assessment could not be correctly achieved. As reported in the materials and methods section, the tests were performed up to approximately $2.5 \mu \mathrm{m}$ and show for both investigated parameters (Young's modulus E and Hardness H) a unique asymptotic behavior for all the samples when the penetration depth is higher than $600 \mathrm{~nm}$, i.e. when higher than the film thickness. At this penetration depth the mechanical property of the substrate assembly (mineral glass + cyanoacrylate glue layer), impact the measured film properties: the characteristics of the films seem to be far lower than the one of the substrate assembly. Nevertheless, the representative values of the films, i.e. for small indentation depth, do not show a fundamental difference between the samples: the elasticity of most of the measured polymers was around 4-6 GPa. The poly(DL-lactide) samples polymerized with iron(III)bromide were inhomogeneous and showed deviations. The polymers exhibit hardness around 0.15-0.25 GPa. The elasticity and hardness characterization by nano-indentation induce interpretation cautions. The results presented here do not represent quantitative values but only trends of comparison since the substrate greatly influences the results. Therefore, the results are not intrinsic mechanical parameters of the considered films only but represent accessible values for the possible thicknesses reached.

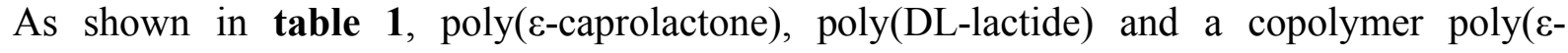
caprolactone-DL-lactide) (50/50) were analyzed by AFM to characterize topographical properties of the systems. The nanoroughness is in the range of $2-11 \mathrm{~nm}$; only $\operatorname{poly}(\varepsilon-$ caprolactone) samples polymerized with iron(III)bromide had a higher nanoroughness of 35 $\mathrm{nm}$. 


\begin{tabular}{|l|l|l|l|l|l|}
\hline Polymer/copolymer & Catalyst & $\begin{array}{l}\text { Average } \\
\text { molecular } \\
\text { weight } \\
\mathbf{M w} \\
{[\mathbf{k g} / \mathbf{m o l}]}\end{array}$ & $\begin{array}{l}\text { Thickness } \\
{[\mathbf{n m}]}\end{array}$ & $\begin{array}{l}\text { Roughness } \\
\text { [nm] }\end{array}$ & $\begin{array}{l}\text { Tack } \\
\text { trend } \\
\text { (adhesi } \\
\text { on) }\end{array}$ \\
\hline PLA & $\mathrm{Sn}(\mathrm{Oct})_{2}$ & 70 & $\begin{array}{l}\text { Not } \\
\text { measurable }\end{array}$ & $\begin{array}{l}\text { Not } \\
\text { measurable }\end{array}$ & \\
\hline PLA & $\mathrm{FeBr}_{2}$ & 48 & 500 & 3 & - \\
\hline PCL & $\left.\mathrm{Sn}_{(\mathrm{Oct})}\right)_{2}$ & 80 & $650-700$ & 11 & + \\
\hline PCL & $\mathrm{FeBr}_{2}$ & 34 & $470-600$ & 35 & - \\
\hline PCLLA $(50 / 50)$ & $\mathrm{Sn}(\mathrm{Oct})_{2}$ & 90 & 470 & 2 & + \\
\hline PCLLA $(50 / 50)$ & $\mathrm{FeBr} 2$ & 22 & 180 & 3 & ++ \\
\hline Control & Pure glass & & & & \\
\hline
\end{tabular}

Table 1 Polymers used for cell studies with human preadipocytes. PCL=Poly( $\varepsilon$-caprolactone), PLA=Poly(DL-lactide), PCLLA=Poly( $\varepsilon$-caprolactone-co-DL-lactide)

\subsection{First set of experiments: human preadipocytes}

In the first set of experiments the focus was on the influence of the catalysts. Each biopolymer sample was synthesized two times, one using tin(II)octanoate as a catalyst and the other with iron(II)bromide or iron(III)perchlorate according to reported literature. ${ }^{[5]}$

Human primary cells from four different donors were used, four experiments were performed for each polymer type, and the cells were counted three times each time a measurement was made. Cells were counted on day 1 and after 2, 4, 7, 9 and 11 days. The results are plotted in figure 1 . 


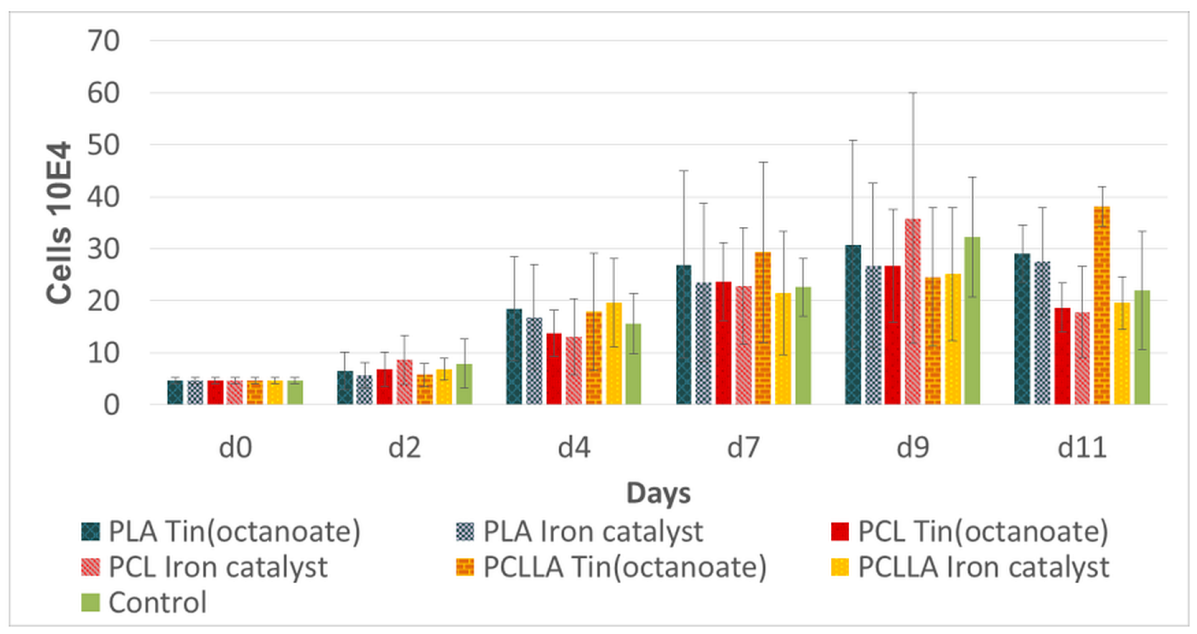

Figure 1 Average cell growth of human preadipocyte cells on the polymer films and the glass control as function of time. No preference for one polymer or catalyst is generalizable.

In two of four cases, the number of cells was not enough to perform the analysis on the last day, day 11. As the results differ substantially from cell to cell, only results up to day 9 were analyzed.

The cell compatibility of different polymers was examined regarding the influence of composition, catalyst, mechanical and topological properties. The tests were conducted with primary cells of rats and humans. The sample consisted in all cases of spin-coated glass slides. The cell growth on different polymer films as well as on the control is similar. In order to validate the impact of the catalyst, the cell growth of human preadipocytes was analyzed disregarding the influence of the polymers, shown in figure 2. 


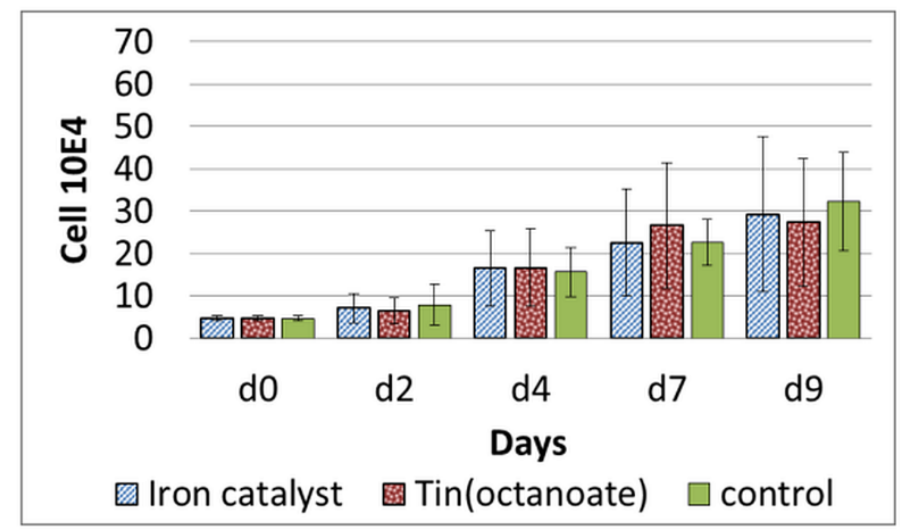

Figure 2 Average cell growth (human preadipocytes) as function of time, disregarding the influence of the polymers. Cells growth on all surfaces is similar, no preference for a specific catalyst is found for short term $2 \mathrm{D}$ experiments.

The preadipocytes seem to grow slightly better on the iron-catalyzed samples, but the difference is not significant. The noticeable small effect of the catalysts towards cell compatibility is supported by a study of Schappacher et al. They analyzed the cytotoxicity of poly(caprolactone) samples, polymerized with different catalysts, and the effects of the catalysts were found to be quite similar. ${ }^{[13]}$ It is important to state, that these short time experiments only show acute toxicity and surface effects. Deviations result from cell-based diversity, as there is a cell to cell difference for catalyst and polymer preference if differences are not critical/toxic.

The next step was to analyze the influence of the polymers while disregarding the influence of the different catalysts, see figure 3. We find no clear preference of the cells for one surface.

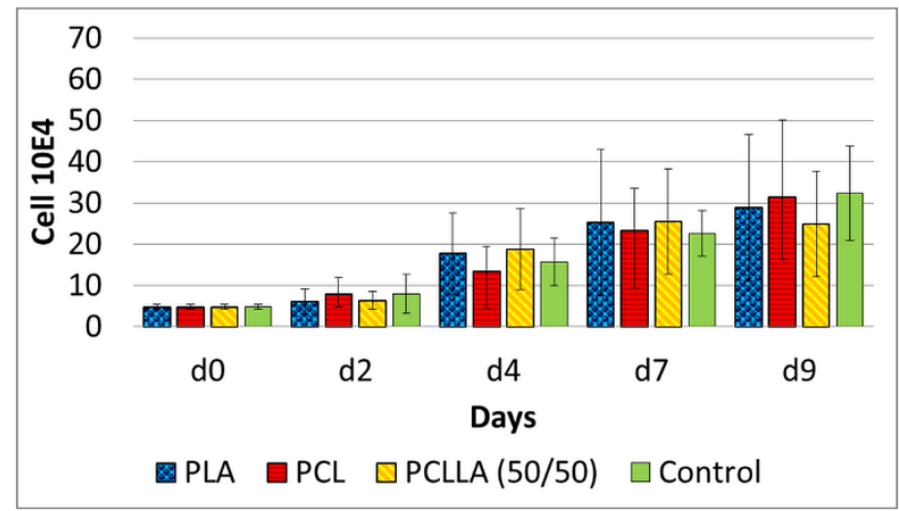


Figure 3 Average cell growth (human preadipocytes) as function of time, disregarding the influence of the catalysts.

The last aspect examined, was the surface roughness, measured by AFM and reported in table 1 and table 2. In figure 4 the cell growth is presented in ascending order depending on the roughness of the polymer surfaces. In the case of the roughest surface with roughness $35 \mathrm{~nm}$, the cell growth increases continuously. At day 9 one finds a preference for the roughest surface and a tendency of higher cell growth on higher roughness. The difference was not significant, but there was a tendency (ANOVA(Roughness): 0.3). The Tukey HSD test also showed that the p-value was smaller the bigger the roughness difference was. So nanoroughness seems to be a positive property human preadipocytes. The effect becomes more pronounced with time.

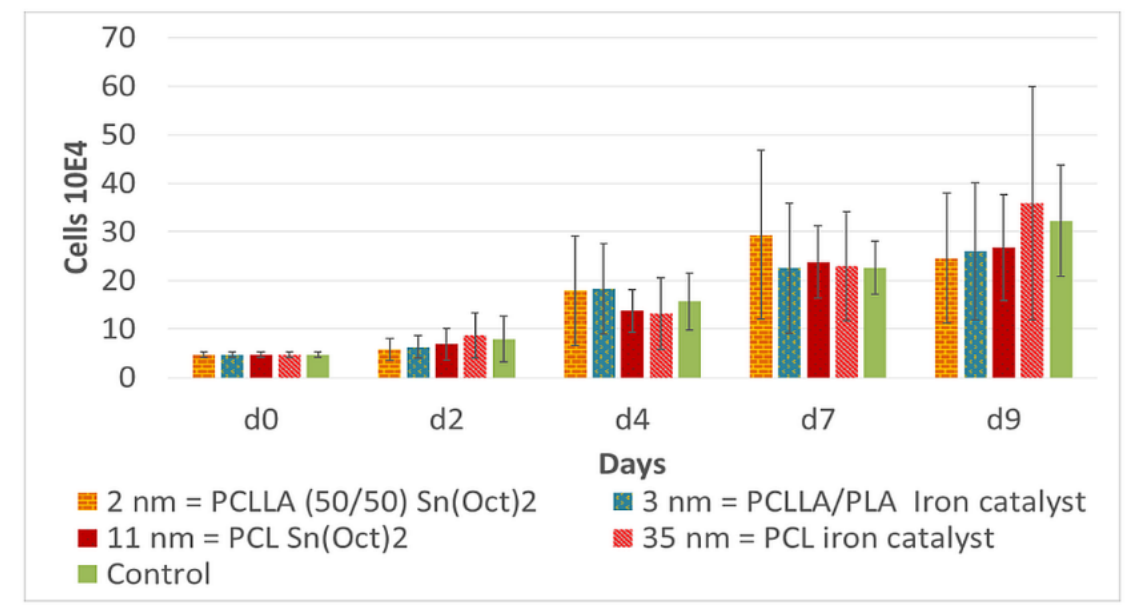

Figure 4 Average cell growth (human preadipocytes) listed as a function of time with respect to surface roughness in ascending order of roughness. At day 9 there is a preference for the roughest surface. This matches the findings of a study of Chung et al. who found that fibroblast prefer nanorough surfaces in contrast to smooth surfaces. ${ }^{[22]}$ 
3.2 Second set of experiments: rat preadipocytes

The main focus of the second set of experiments was the influence of the chemical composition of the polymers. Here only one variation of each polymer was used, in order to be able to analyze a large diversity polymers. Five polymers were analyzed: poly $(\varepsilon-$ caprolactone), poly(e-caprolactone-co-DL-lactide) (PCLLA, 50:50), poly(DL-lactide-coglycolide) (PLGA, 75/25), poly(DL-lactide-co-glycolide) (PLGA, 80/20) and poly( $\varepsilon$ caprolactone-co-DL-lactide-co-glycolide) (PCLLAGA, 60/25/15). The molecular weight and roughness of these polymers are given in table 2.

\begin{tabular}{|l|l|l|l|l|l|}
\hline Polymer/copolymer & Catalyst & $\begin{array}{l}\text { Average } \\
\text { molecular } \\
\text { weight } \mathbf{M w} \\
{[\mathbf{k g} / \mathbf{m o l}]}\end{array}$ & $\begin{array}{l}\text { Thickness } \\
{[\mathbf{n m}]}\end{array}$ & $\begin{array}{l}\text { Roughness } \\
{[\mathbf{n m}]}\end{array}$ & $\begin{array}{l}\text { Tack trend } \\
\text { (adhesion) }\end{array}$ \\
\hline PLGA (75/25) & $\mathrm{Sn}(\mathrm{Oct})_{2}$ & 50 & 240 & 1 & ++ \\
\hline PLGA (80/20) & $\mathrm{Sn}(\mathrm{Oct})_{2}$ & 39 & 190 & 3 & -- \\
\hline PCLLA (50/50) & $\mathrm{Fe}(\mathrm{ClO})_{3}$ & 22 & 180 & 3 & ++ \\
\hline PCL & $\mathrm{Sn}(\mathrm{Oct})_{2}$ & 80 & $650-700$ & 11 & + \\
\hline PCLGA (80/20) & $\mathrm{Sn}(\mathrm{Oct})_{2}$ & 66 & 360 & 14 & -- \\
\hline $\begin{array}{l}\text { PCLLAGA } \\
(65 / 25 / 15)\end{array}$ & $\mathrm{Sn}(\mathrm{Oct})_{2}$ & 53 & & $\begin{array}{l}\text { Could not be } \\
\text { measured }\end{array}$ & $\begin{array}{l}\text { Could not be } \\
\text { measured }\end{array}$ \\
\hline Control & & & & & \\
\hline
\end{tabular}

Table 2 Polymers used for rat preadipocyte cell cultures. PCL $=$ Poly( $\varepsilon$-caprolactone), PCLLA = Poly( $\varepsilon$-caprolactone-co-DL-lactide), PLGA: Poly(DL-lactide-co-glycolide) PCLGA $=$ Poly $(\varepsilon$-caprolactone-co-glycolide $)$, PCLLAGA $=$ Poly $(\varepsilon$-caprolactone-co-DLlactide-co-glycolide).

For the second set of experiments, polymer samples were prepared with a difference in nanoroughness of only $10 \mathrm{~nm}$. Nearly all polymers except one were synthesized with tin(II)octanoate. Primary cells from five rats were used. The cells were counted at day $0, d 2$, d4, d7, d9 and d11. The results are shown in figure 5. 


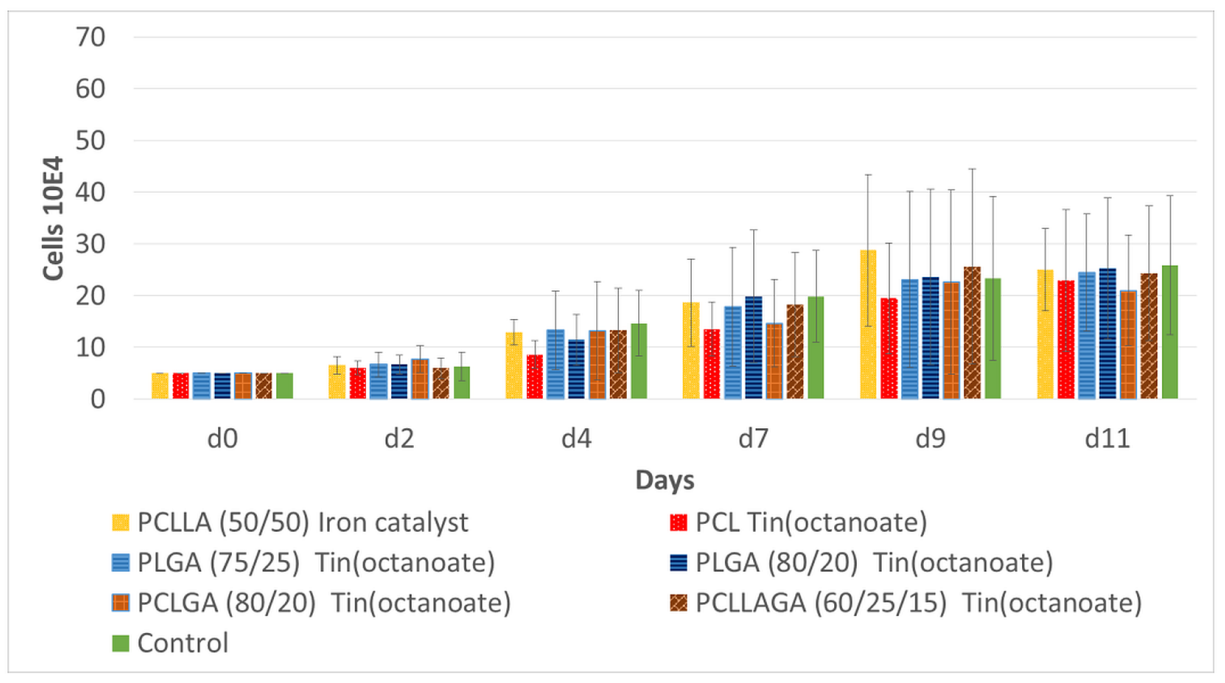

Figure 5 Average cell growth of rat preadipocytes on polymer films and glass control as function of time.

The iron catalyzed PCLLA (50/50) sample is among the best surfaces at nearly all days investigated, see figure 2. At day 9 , it is slightly better than the other surfaces. Poly $(\varepsilon-$ caprolactone-DL-lactide) also showed good performance in the first part of the study, see figure 1 .

Poly( $\varepsilon$-caprolactone) is part of nearly all polymer compositions in the second part of the study. The polymer compositions contain poly( $\varepsilon$-caprolactone) in different ratios. To investigate if there is a monomer ratio of the copolymer, which is preferred by rat preadipocytes, the average cell growth was ordered in respect to an increasing $\varepsilon$-caprolactone ratio (see figure 6). In case of the PLGA samples, the average value was used. 


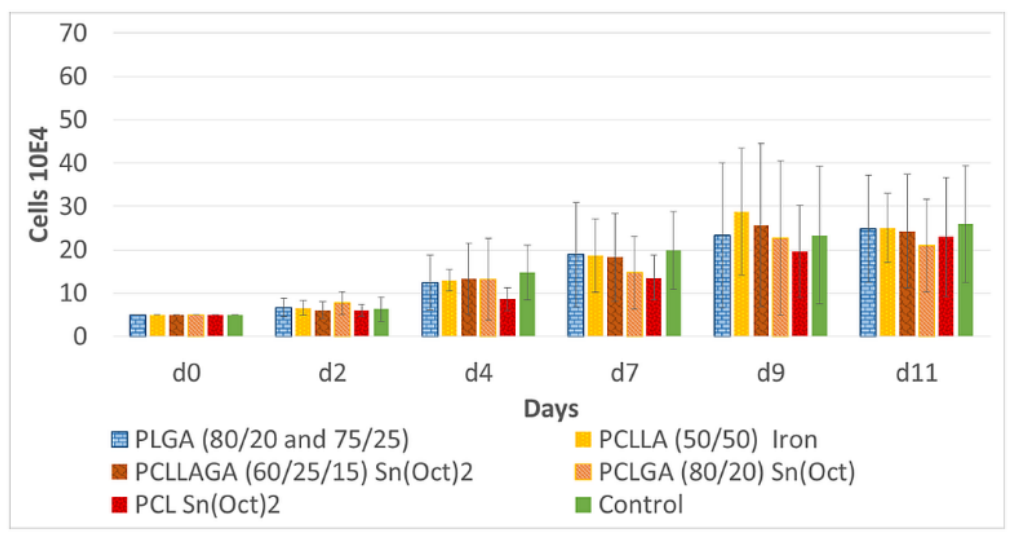

Figure 6 Average cell growth of rat preadipocytes shown as a function of time in ascending order of $\varepsilon$-caprolactone ratio. Until day 11 the cell density on poly( $\varepsilon$-caprolactone) films is significantly lower than on the other polymer films.

Until day 11 the cell density is lowest on the pure poly( $\varepsilon$-caprolactone) sample. At day 7 and 9 the cell density decreases with increasing $\varepsilon$-caprolactone-ratio. An explanation for this could be that with increasing $\varepsilon$-caprolactone ratio the hydrophobicity also increases. The hydrophobicity seems to slow down cell proliferation. This matches the study of Altankov et al. who compared the biocompatibility of hydrophobic and hydrophilic surfaces with the result that the hydrophilic surfaces are better for the cells than the hydrophobic. ${ }^{[29]}$ At day 11 the cell density is on nearly the same level on all surfaces. On the PCLLA-surfaces the cell density is significantly higher than on poly( $\varepsilon$-caprolactone)-surfaces (ANOVA(PCLLA/PCL: 0.02). Another reason why the PCLLA-surface could be preferred, could be the better adhesion on PCLLA compared with the PCL-surface. Comparing the best adhesive surfaces (PCLLA and PLGA (80/2) with PCL leads to significant results (ANOVA(PCLLAPLGA80/PCL: 0.024). However, no significant influence of the adhesion could be shown in the first set of experiments.

In case the of the types of polymers, the study showed that the cell compatibility of the polymers does not differ significantly. This is in line with the study of Pariente et al. who 
analyzed different natural and synthetic biomaterials concluding that all tested materials are biocompatible. ${ }^{[10]}$

\subsection{Comparisons}

The studied biopolymer systems provide important insights for material design in tissue engineering and cell culture application. The use of biopolymers with distinct compositions and surface properties are exemplified and validated for 2D cell cultures.

Concerning the cell compatibility of the catalysts no statistical influence could be seen in time frame typical for $2 \mathrm{D}$ cultures. In the second set of experiments, iron-catalyzed $\operatorname{poly}(\varepsilon-$ caprolactone-co-lactide) was significantly better then the tin-catalyzed poly(e-caprolactone). However, in the first set of experiments the tin-catalyzed poly( $\varepsilon$-caprolactone-co-lactide) showed better cell compatibility then the iron-catalyzed. Since the absolute differences are minor, one cannot infer a strict preference for one catalyst over another despite statistic significance.

In contrast nanoroughness does seems to have a pronounced influence on cell compatibility of the surfaces. The iron-catalyzed poly( $\varepsilon$-caprolactone) sample showed substantial growth by day 9 , see figure 1 . The nanoroughness of this polymer sample is with $35 \mathrm{~nm}$ the largest surface roughness of all polymer systems investigated, see figure 5. In the first set of experiments, one can also see that the cell density increases with increasing nanoroughness. This matches the findings of a study of Chung et al. who found that fibroblasts prefer nanorough surfaces in contrast to smooth surfaces. ${ }^{[22]}$ If the difference of the nanoroughness is only around $10 \mathrm{~nm}$, as found in set 2, no influence of the roughness is found. This matches the study of Xie et al. which also showed no influence if the difference in nanoroughness was smaller as $12 \mathrm{~nm} .{ }^{[30]}$

\subsection{Differentiation experiments}


Differentiation experiments were performed to examine the impact of different surfaces on the differentiation of preadipocytes. In order to investigate this question, cells were differentiated according to the method mentioned in section 2.5.4.

Regarding differentiation there is no obvious difference between different polymer systems or catalysts investigated; the adipocyte density resides in the same range. However, there is a big disparity between the polymer surfaces and the glass control (see supporting information). The adipocyte density is nearly 9 times lower than on the polymer surfaces. This is a clear indicator that polymer surfaces are better for adipocyte differentiation than glass.

\section{Conclusions}

The biopolymer systems studied represent a vast range of chemical entities and conditions covering important applicable combinations of the three major FDA-approved biopolmyers in use. Major factors for materials used in tissue engineering such as the type of biopolymer, combinations thereof, effect of catalysts used in biopolymer synthesis as well as mechanical properties and surface topological effects (roughness) could be validated and give important guidelines for the use of biopolymers and their effects exemplified and validated for 2D cell cultures.

Neither the polymer, nor the catalyst nor the mechanical properties have a critical influence on cell behavior. One exception concerning the polymer compatibility was found for rat preadipocytes which significantly preferred the PCLLA-surface over the PCL-surface. Probably this is because of PCL's higher hydrophobicity compared to PCLLA. This is in line with a study of Altankov et al. who showed that cells prefer hydrophilic surfaces. ${ }^{[29]}$ Also the better adhesion of cells on the PCLLA surface compared to the PCL surface can be important. The role of the catalyst was shown to have no critical effect in the context of these studies if cell proliferation and differentiation is concerned. This may be attributed to a limited liberation of catalyst from the material: the catalyst able to diffuse out of the material will be 
quickly eluted and distributed within the comparably large volume of the culture media, in addition biopolymer degradation is low within the time frames investigated.

Increased nanoroughness seems to be advantageous for preadipocytes, and should be subject of further studies. If the nanoroughness is comparable for all slides, for example in the second set of experiments, the material composition becomes more important.

Concerning the differentiation, no polymer-specific effect could be identified, which significantly stimulates differentiation. But the comparison of the polymer films and the pure glass slides showed big differences. On the polymer films many preadipocytes differentiated into adipocytes (see Supporting Information). In contrast to this finding, nearly no preadipocytes differentiated on pure glass samples despite the applied differentiation cocktail. So as a major finding we can postulate that differentiation of preadipocytes favors polymer surfaces in contrast to glass surfaces.

In sum we can conclude that the type/chemical composition and catalyst as well as mechanical properties have limited influence on preadipocyte cell cultures. It could be shown, that a nanoroughness of $35 \mathrm{~nm}$ in contrast to $10 \mathrm{~nm}$ has a positive effect of preadopocytes. Therefore the type of biopolymer to be chosen for certain biomedical applications may be attributed to specific needs of the application such as mechanical stiffness, time of degradation and processability. This is an important and promising finding fostering a multitude of applications such as current efforts towards porous scaffolds for 3D tissue replacement explored by us.

\footnotetext{
Abbreviations

$\mathrm{PCL}=\operatorname{Poly}(\varepsilon$-caprolactone $)$

PLA $=$ Poly $($ DL-lactide $)$

PCLLA $=$ Poly $(\varepsilon-$ caprolactone-co-DL-lactide $)$

PLGA: Poly(DL-lactide-co-glycolide)
} 
PCLGA $=$ Poly $(\varepsilon$-caprolactone-co-glycolide $)$

PCLLAGA = Poly( $\varepsilon$-caprolactone-co-DL-lactide-co-glycolide $)$

Acknowledgements: We gratefully acknowledge the support of the BMBF (Research Prize Next Generation of Biotechnological Processes 2014 Biotechnology2020+, FK: 031A550), the Zentrum für Biosystem Analyse (ZBSA), the Freiburg Institute for Advanced Studies (FRIAS), the institute for macromolecular chemistry, the Institute for Micro System Engineering (IMTEK) \& EXC 294 BIOSS Centre for Biological Signalling Studies and the Rectorate of the University of Freiburg for support. We want to thank Birgit Schreiner and Ulrike Schmidt for the cell experiments. And, especially Ulrike Schmidt for the valuable help by writing the article. We also would like to thank Marina Hagios for GPC measurements.

\section{References}

[1] Gunatillake, P. A.; Adhikari, R; Biodegradable Synthetic Polymers for Tissue Engineering, Eur. Cell. Mater. 2003, 5, 1-16.

[2] Woodruff, M. A.; Hutmacher, D. W. The return of a forgotten polymerPolycaprolactone in the 21st century. Progress in Polymer Science 2010, 35, 1217-1256.

[3] Tanzi, M. C.C.; Verderio, P.; Lampugnani, M. G.; Resnati, M.; Dejana, E.; Sturani, E. Cytotoxicity of some catalysts commonly used in the synthesis of copolymers for biomedical use. Journal of materials science. Materials in medicine 1994, 5, 393-396.

[4] Arbaoui, A.; Redshaw, C. Metal catalysts for $\varepsilon$-caprolactone polymerisation. Polym. Chem. 2010, 1, 801. 
[5] Hege, C. S.; Schiller, S. M. Non-toxic catalysts for ring-opening polymerizations of biodegradable polymers at room temperature for biohybrid materials. Green Chem 2014, 16, $1410-1416$.

[6] Gowda, R. R.; Chakraborty, D. Zinc acetate as a catalyst for the bulk ring opening polymerization of cyclic esters and lactide. Journal of Molecular Catalysis A: Chemical 2010, $333,167-172$.

[7] Dove, A. P. Organic Catalysis for Ring-Opening Polymerization. ACS Macro Lett. 2012, $1,1409-1412$.

[8] Kobayashi, S. Enzymatic ring-opening polymerization and polycondensation for the green synthesis of polyesters. Polym. Adv. Technol. 2015, 26, 677-686.

[9] Kanitkar, A.; Smoak, M.; Chen, C.; Aita, G.; Scherr, T.; Madsen, L.; Hayes, D. Synthesis of novel polyesters for potential applications in skin tissue engineering. J. Chem. Technol. Biotechnol. 2016, 91, 733-741.

[10] Pariente, J.-L.; Kim, B.-S.; Atala, A. In vitro biocompatibility evaluation of naturally derived and synthetic biomaterials using normal human bladder smooth muscle cells. The Journal of urology 2002, 167, 1867-1871.

[11] Sliedregt, A.; Radder, A. M.; Groot, K.; Blitterswijk, C. A. In vitro biocompatibility testing of polylactides Part I Proliferation of different cell types. J Mater Sci: Mater Med 1992, 3, 365-370.

[12] Rogero, S. O.; Malmonge, S. M.; Lugão, A. B.; Ikeda, T. I.; Miyamaru, L.; Cruz, Á. S. Biocompatibility study of polymeric biomaterials. Artificial Organs 2003, 27, 424-427. 
[13] Schappacher, M.; Le Hellaye, M.; Bareille, R.; Durrieu, M.-C.; Guillaume, S. M. Comparative in vitro cytotoxicity toward human osteoprogenitor cells of polycaprolactones synthesized from various metallic initiators. Macromolecular bioscience 2010, 10, 60-67.

[14] Stjerndahl, A.; Wistrand, A. F.; Albertsson, A.-C. Industrial utilization of tin-initiated resorbable polymers: synthesis on a large scale with a low amount of initiator residue. Biomacromolecules 2007, 8, 937-940.

[15] Brackett, M. G.; Marshall, A.; Lockwood, P. E.; Lewis, J. B.; Messer, R. L. W.; Bouillaguet, S.; Wataha, J. C. Cytotoxicity of endodontic materials over 6-weeks ex vivo. International Endodontic Journal 2008, 41, 1072-1078.

[16] Bergsma, J. E.; Bruijn, W. C. de; Rozema, F. R.; Bos, R. R. M.; Boering, G. Late degradation tissue response to poly (L-lactide ) bone plates and screws. Biomaterials 1995, $16,25-31$.

[16] Kobayashi, H.; Shiraki, K.; Ikada, Y. Toxicity test of biodegradable polymers by implantation in rabbit cornea. J. Biomed. Mater. Res. 1992, 26, 1463-1476.

[18] Robert, P.; Mauduit, J.; Frank, R. M.; Vert, M. Biocompatibility and resorbability of a polylactic acid membrane for periodontal guided tissue regeneration. Biomaterials 1993, 14, $353-358$.

[19] Gourlay, S. J.; Rice, R. M.; Hegyeli, A. F.; Wade, C. W.; Dillon, J. G.; Jaffe, H.; Kulkarni, R. K. Biocompatibility testing of polymers: In vivo implantation studies. J. Biomed. Mater. Res. 1978, 12, 219-232. 
[20] Kunzler, T. P.; Drobek, T.; Schuler, M.; Spencer, N. D. Systematic study of osteoblast and fibroblast response to roughness by means of surface-morphology gradients. Biomaterials 2007, 28, 2175-2182.

[21] Richards, R. G. The effect of surface roughness on fibroblast adhesion in vitro. Injury 1996, 27 Suppl 3, SC38-43.

[22] Chung, T.-W.; Wang, S.-S.; Wang, Y.-Z.; Hsieh, C.-H.; Fu, E. Enhancing growth and proliferation of human gingival fibroblasts on chitosan grafted poly (lepsilon-caprolactone) films is influenced by nano-roughness chitosan surfaces. J Mater Sci: Mater Med 2009, 20, $397-404$.

[23] Gittens, R. A.; McLachlan, T.; Olivares-Navarrete, R.; Cai, Y.; Berner, S.; Tannenbaum, R.; Schwartz, Z.; Sandhage, K. H.; Boyan, B. D. The effects of combined micron-/submicron-scale surface roughness and nanoscale features on cell proliferation and differentiation. Biomaterials 2011, 32, 3395-3403.

[24] Hutter, J. L.; Bechhoefer, J. Calibration of atomic-force microscope tips. Review of Scientific Instruments 1993, 64, 1868-1873.

[25] Villarrubia, J. S. Morphological estimation of tip geometry for scanned probe microscopy. Surface Science 1994, 6028, 287-300.

[26] Oliver, W. C.; Pharr, G. M. Measurement of hardness and elastic modulus by instrumented indentation: Advances in understanding and refinements to methodology. Journal of Materials Research 2004, 19, 3-20.

[27] Van, R. L. R.; Bayliss, C. E. Roncari, A. K.; Cytological and enzymological characterization of adult human adipocyte precursors in culture, J. Clin. Invest, 1976, 58(3), $699-704$ 
[28] RStudio Team (2016), RStudio: Integrated Development for R. RStudio, Inc., Boston, MA, URL http://www.rstudio.com/

[29] (Altankov, G.; Groth, T. Reorganization of substratum-bound fibronectin on hydrophilic and hydrophobic materials is related to biocompatibility. J Mater Sci: Mater Med 1994, 5, 732-737.

[30] Xie, Y.; Sproule, T.; Li, Y.; Powell, H.; Lannutti, J. J.; Kniss, D. A. Nanoscale modifications of PET polymer surfaces via oxygen-plasma discharge yield minimal changes in attachment and growth of mammalian epithelial and mesenchymal cells in vitro. J. Biomed. Mater. Res. 2002, 61, 234-245. 